\title{
Smartphone Addictions: A Review of Themes, Theories and Future Research Directions
}

\author{
Boateng Richard \\ University of Ghana \\ richboateng@ug.edu.gh
}

\author{
Makafui Nyamadi \\ University of Ghana \\ mnyamadi@st.ug.edu.gh
}

\author{
Immaculate Asamenu \\ Ho Technical University \\ iasamenu@htu.edu.gh
}

\begin{abstract}
This research work presents a literature review on "Smartphone Addiction" (SA). The papers used for this review were retrieved from AIS (All Repositories), Elsevier, Wiley Online, Tailor and Francis and JSTOR databases using the phrase "Smartphone Addiction". In all, 13 AIS top conferences and 31 peer-reviewed journals searched from 2007 to July 2018 returned 1572 papers. This paper details the findings based on the literature assessment of 128 publications. In terms of context and geographical gaps, Asia leads the chart with 39 articles representing 30.5percent and Africa recorded only 1 paper used for this work. Online data collection with global focus had 37 articles representing 28.9percent and quantitative methodology was adopted by 91 articles representing 71.1 percent. $S A$ research was more at the micro and meso levels. This review has demonstrated that literature offers several perspectives on SA but failed to establish a causal theory or a model that fully accounted for urge and craving phenomena from an IS design principle perspective to mitigate SA. Also, smartphones are devices (artifacts) that enable users to access and become addicted to applications such as video games, SNSs, emails, etc. Future research should, therefore, focus more on addictive activities and applications on these devices.
\end{abstract}

\section{Introduction}

There is an emerging trend of addictive usage of smartphones in recent times[1]-[3]. This emergence has engaged various professionals and researchers in diverse disciplines of which Information Systems (IS) is of no exception [4], [5]. Addiction is defined as the compulsion to repeat a behavior regardless of its consequences [6], [7]. It has been researched in diverse habit-forming contexts, including cigarettes [8], alcohol [9], cocaine [10], opium [11], caffeine [12], pathological gambling [13], [14] and so on. In recent times, several technologies are being addicted to by users. The main umbrella term for compulsive, problematic, and dependence and excessive usage of IT technologies is known as 'Technology Addiction' (TA) which is of a serious concern to Information Systems (IS) scholars [15]. There are several forms of technology addictions that have engaged the attention of researchers such as excessive microblogging [16], cyberloafing [17], online games [18], [19], internet

URl: https://hdl.handle.net/10125/64488

978-0-9981331-3-3

(CC BY-NC-ND 4.0)

[20], [21], mobile email [22], instant messaging [23], [24], online auction [25], Social Network Site (SNS) [26] and IT [27], [28]. The above-listed technologies are examples of the addictive applications accessed by users on smartphones. As such, smartphones in themselves may not be addictive but are platforms on which these applications which tend to cause users to be addicted are installed and accessed[29], [30].

A smartphone is the infusion of Personal Digital Assistant (PDA) and mobile phones. It functions as a device that gives access to videos, voice and image communications[31]. They are also used for playing games, shopping, and information-seeking [32]-[34]. The use of smartphones has become a social phenomenon, taking place within a social context and influenced by perceptions of products, services, and social norms [35]. As smartphone penetration becomes prominent, its compulsive and addictive trends have emerged as a growing concern to all stakeholders. Smartphone addiction involves excessive interactions with a smartphone device with a special focus on the functions it provides and the applications accessed on it [22]. Anecdotal evidence on instances of compulsive behaviors in the use of smartphones includes checking habits [36], phantom vibrations [37], a cycle of responsiveness[38], and loss of impulse [39].

Literature review refers to the aggregation or accumulation of research work by "building on each other's (research) results" [40]. Weber and Watson suggested that literature review helps to create a "firm foundation for advancing knowledge" [41]. Sir Isaac Newton wrote a letter to Robert Hooke in 1675 stating that "if I have seen further it is by standing on the shoulders of giants"[42]. Vreede and Briggs further specified that "the significance of academic research work is materialized when it is published"[43]. This review, therefore, uses papers published in either conferences or journals. Top IS conference articles are considered because Weber and Watson suggested that in reviewing literature in IS, scholars "should also examine the selected conference proceedings, especially those with a reputation for quality"[41].

Smartphone addiction or problematic usage of smartphone literature review has been published from psychology, psychiatric or mental health discipline; such reviews were mainly skewed towards consequences such as stress, anxiety, depression severity, extraversion, self-identity, neuroticism, self- 
image, etc [44], [45]. Tarafdar, Gupta, and Turel suggested that to study technology addiction and by implication, smartphone addiction, scholars should understand the antecedents and outcomes or consequences [46]. Therefore, it would be useful to review literature from antecedents to consequences of SA by considering papers mainly but not limited to IS discipline or domain. The purpose of this review is to help bring to the fore the overview of where research on SA has reached in terms of publication outlets, themes, year of publication, methodology, level of analysis, geographical focus, frameworks/models/ theories in order to provide a solid foundation for future research and to assist in mitigating or preventing SA.

This paper is organized as follows: the first section is the introduction; followed by the methodology used for the review and findings. The final section is the discussions, conclusions, limitations and future research directions.

\section{The Methodology Used for the Review}

This research work adopted a methodological approach that allowed the review to be supported by statistical data, sometimes presented in graphs to give a clear meaning to the reader. This review was done with a special focus on conference literature published in the AIS database. Journals were retrieved from AIS Senior Basket, Elsevier, Wiley Online, Tailor and Francis, and JSTOR databases using the phrase "Smartphone Addiction". The practice of using the electronic database for a review was deemed appropriate because it is a common phenomenon among Information Systems scholars[47], [48]. The first search based on the title, keyword, abstract, and general content returned 1572 articles. Dissertations, technical reports, book chapters, and others were excluded. Only journal and conference articles were considered. In the next phase, each article was examined to determine their novel contributions to SA literature and not just references. Seventy-three (73) journal publications and fifty-five (55) top-ranked Association of Information Systems (AIS) conference articles met the criteria and were used for this work.

For the journal articles, the search was done at the database level; however, the AIS baskets journals were searched individually at the journal level using the word "Smartphone Addiction". The 73 journal articles accepted and used for this piece were from the following; Computers in Human Behavior, European Journal of Information Systems, Information Systems Journal, Information Systems Research, Communications of the Association for Information Systems, Pervasive and Mobile Computing, Accident Analysis and Prevention journal, Clinical Psychology
Review, Neurocomputing, Journal of Substance Abuse and Treatment, Telematics and Informatics, Children and Youth Services Review, Journal of Economic Psychology, Addictive Behaviors, Psychiatric Research, Computers and Composition, Nurse Education Today, Heliyon, Child Abuse \& Neglect, Organizational Dynamics, International Journal of Human-Computer Interaction, The Journal of Biological and Medical Rhythm Research, Personality and Individual Differences, Public Health, Communicatio, Procedia Social and Behavioral Sciences, Drug and Alcohol Dependence, Journal of High Technology Management Research, Journal of Affective Disorders, Computers \& Education and Asian Nursing Research.

For the conferences, all Information Systems (IS) conferences on AIS electronic library were first and foremost searched to determine the conferences that published articles related to SA, it was found that 13 conferences did publish on SA, these conferences were; The Americas Conference on Information Systems (AMCIS); Bled eConference, European Conference On Information Systems (ECIS); Hawaii International Conference on System Sciences (HICSS); International Conference on Information Systems Development (ISD); The International Conference on Information Systems (ICIS); International Conference on Mobile Business (ICMB); Mediterranean Conference on Information Systems (MCIS); Pacific Asia Conference On Information Systems (PACIS); Special Interest Group on Computer-Human Interaction (SIGCHI); Southern Association for Information Systems Conference (SAIS); Wuhan International Conference on e-Business (WHICEB), and Wirtschatfsinformatik Conference. In the second phase, each conference was searched using the word "Smartphone Addiction" which helped the researchers to accept, 55 articles from the 13 conferences for this paper; this practice is aligned with other studies [49]-[51].

The classifications considered Global, Cross Continents, Asia, North America, South America, Australia, and Africa. The levels of analysis that were taken into consideration in this research are as follows; micro, macro, meso, and meta levels. This review also considered theories, models, frameworks that guided the 128 articles used for this review.

The conference papers reviewed were categorized into four (4) subthemes, namely pre-addiction, addiction, post-addiction, and pre/post addictions. The pre-addiction subthemes looked at the factors that influence or cause a user to be addicted to the smartphone. The addiction subtheme papers looked at the prevalence, pervasiveness, predominance and or rivalry among different smartphone user groups. The post-addiction focused on the effect of addiction on the livelihood of addicts and treatment measures or 
discontinuation. The pre/post addiction papers looked at factors leading to smartphone addiction and the consequences of the addictions. They were papers that put together from pre to post subthemes in one publication [52], [53].

\section{Presentation of Findings}

\subsection{Publication outlets}

The respective outlets and their distributions are as follows; Computers in Human Behavior came up with the highest published articles accepted on SA and scored 25.8 percent. European Journal of Information Systems, Information Systems Journal, and Telematics and Informatics were second with 2.3 percent, Children and Youth Services Review, International Journal of Human-Computer Interaction; Psychiatric Research came third with 1.6 percent. All the other journal outlets used for this review had one publication each amounting to 0.8 percent each.

Among the conferences, Pacific Conference on Information Systems (PACIS) published the highest number of 13 articles and scored 10.2 percent accepted for this work. It is the leading AIS conference dedicated to the Pacific Asia Region endorsed by AIS Council and has been running since 1993. The International Conference on Information Systems (ICIS) and the Americas Conference on Information Systems (AMCIS) came up with 10 publications each amounting to 7.8 percent respectively. ICIS is the most revered and prestigious conference of IS academics, researchers and practitioners in the world. It was founded in 1980. Also, AMCIS is one of the leading conferences presenting the broadcast variety of research done by and for IS/ IT and is organized mainly around the United States of America (USA). It has been running since 1995 .

The European Conference on Information Systems (ECIS) and The Hawaii International Conference on System Sciences (HICSS) came up with 5 publications each and scored 3.9 percent respectively. ECIS is one of the leading, IS conferences, recognized by AIS and dedicated to the European Region. The Hawaii International Conference on System Sciences (HICSS) is an annual conference for Information Systems (IS) and Information Technology (IT) researchers and professionals sponsored by the University of Hawaii at Manoa, it is considered globally by IS scholars as one of the prestigious conferences for IS/IT scholars, academics and practitioners. It was started in 1968 and therefore is one of the oldest AIS conferences.

BLED eConference (BLED), International Conference on Mobile Business (ICMB), Mediterranean Conference on Information Systems
(MCIS), and Wirtschaftinformatiks came up with 2 publications each scoring 1.6percent. BLED eConference (BLED) is a conference tailored towards shaping electronic interactions. It was started in 1988. The conference venue is Alpine Village of Bled, $30 \mathrm{~km}$ South of Austria border. ICMB was a conference dedicated to mobility and mobile business, founded in 2002 in Athens. MCIS is focused on Mediterranean Regions, and Wirtschaftinformatiks is the premier conference of IS scholars in German-speaking communities.

International Conference on Information Systems Development (ISD), Southern Association for Information Systems (SAIS), Special Interest Group on Computer-Human Interaction (SIGCHI) Conference (SIGHCI), and Wuhan International Conference on EBusiness (WHICEB) individually published 1 article each and therefore scored 0.8 percent points respectively.

\subsection{Research themes}

Tarafdar, Gupta, and Turel posited that to study technology addiction and by implication, smartphone addiction, scholars should understand the antecedents and outcomes or consequences [46]. Therefore, the articles reviewed were categorized into four (4) subthemes, namely pre-addiction, addiction, post addictions, and pre/post addictions to link the papers to the antecedents and consequences of smartphone addiction. The detailed classification is shown in Fig. 1 below:

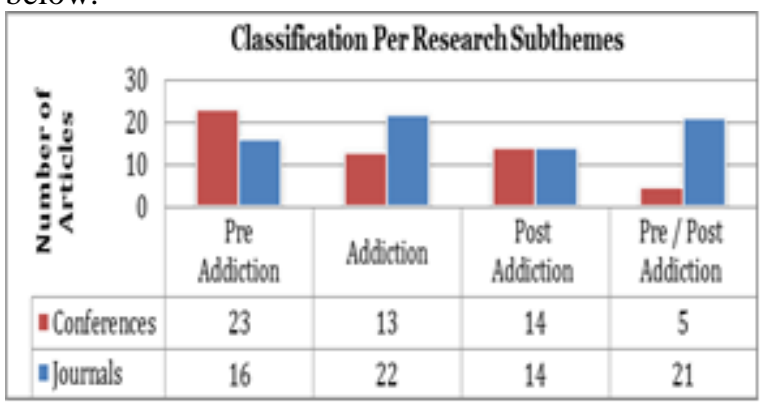

Fig. 1. Classification per research subthemes

The researchers found out that the pre-addiction which constitutes 23 articles from the conferences and 16 articles from journals totaling 39 articles and represented 30.5 percent of the total articles is the highest subtheme. It shows that scholars researching smartphone addictions tried to find out from different perspectives on how technologies and applications influence users to become addicted to smartphones. The second category, known as addiction category, looked at the prevalence, pervasiveness, and predominance among varied smartphone user groups. Thirteen (13) conference articles and 22 journal articles totaling 35 articles which represented 27.3 percent were found in this category. 
The third highest subtheme was post-addiction. Fourteen (14) conference articles and 14 journal articles totaling 28 articles representing 21.9 percent were found in this category. Researches in this category were focused on the effect of addiction on the livelihood of addicts, their immediate environment and treatment measures or discontinuation of addiction. The fourth category of papers looked at pre to postaddiction. Scholars in this category were researching into factors leading to smartphone addiction, prevalence and the consequences of addictions. 21 journal articles and 5 conference articles totaling twenty-six (26) articles representing 20.3 percent were found in this category.

\subsection{Year of publication}

The classification by year of publication showed an interesting result. The period covered was from 2007 to June 2018. In 2007, there was 1 publication recorded for conference and 0 for journals representing 0.8 percent. In 2008, 1 each was recorded for both conference and journal totaling two 2 publications which represented 1.6 percent. In 2009, there was no journal publication recorded for this review; however, the conference recorded 2, representing 1.6percent. Interestingly, there was no publication recorded on smartphone addiction for both conferences and journals in 2010. In 2011, there was 1 publication recorded for only conferences representing 0.8 percent. In 2012, 5 publications were recorded for conferences and one (1) for a journal totaling 6 publications which represented 4.7 percent. In 2013, 8 publications were recorded for conferences and 3 for journals totaling 11 publications representing 8.6 percent. 13 publications were recorded for conferences and 6 for journals representing 14.8 percent in 2014. 11 articles were recorded for conferences and 10percent for journals totaling 21 which represented $(16.4 \%)$ in 2015.5 articles for publications and eighteen (18) for journals totaling 23 articles representing 18 percent were recorded for 2016.

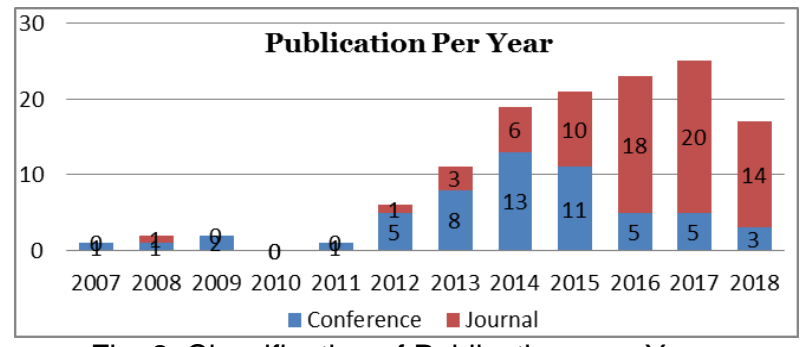

Fig. 2. Classification of Publications per Year

In 2017, the highest articles publications of 25 were recorded and used for this review, 5 of them were for conferences and 20 for journals. The 3 articles recorded for conferences and 14 for journals representing 13.3 percent were published from January to June 2018. It was noticed that interest in the dark side of IT in general and smartphones in particular in the information systems domain started gathering momentum from 2014. The graphical representation of the details of the publications per year is shown above.

\subsection{Research methodology}

Research methodology categorization helped to know the number of articles published using various methods such as quantitative, qualitative, mixed-method and design science. After the analysis, it was realized that quantitative methodology recorded the highest count of 91 articles. 53 articles for journals, and 38 articles were recorded for conferences representing 71.1percent, followed by qualitative with 21 papers with 8 conference articles, and 13 journals articles representing 16.4 percent, mixed-method was the next with 7 conference articles and 5 journal conference totaling 12 articles amounting to 9.4 percent and the experiment and simulation which is usually used in designed science recorded the lowest publication of 4 papers each representing 3.1 percent.

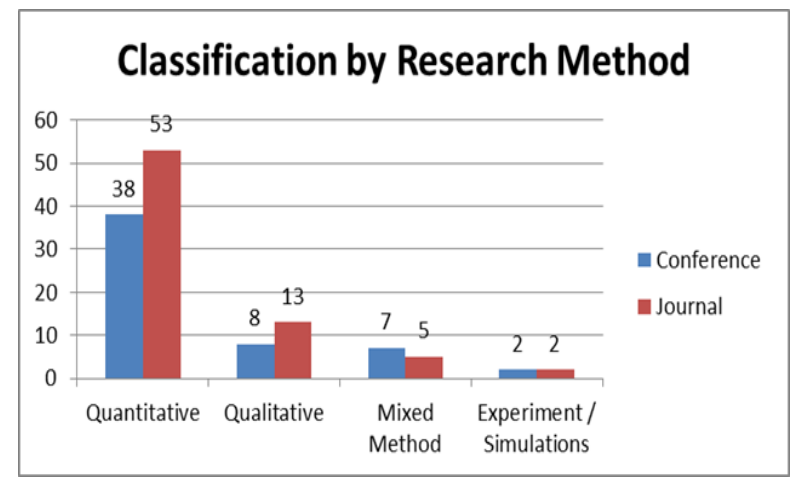

Fig.3. Literature classification by research methodology

\subsection{Level of analysis}

The level of analysis classification of smartphone addiction was done based on micro, meso, macro and meta levels. This classification helped to establish the level of analysis gap which revealed the level at which the research was conducted, and the extent to which the research identified interrelationships between levels of analysis. At the micro-level, the focus of the research was at the organizational/firm-level and individual levels. At the meso-level, the focus was on industry or networks of firms beyond one single firm. At the macro level, the focus was at the national level, this examined the role of institutions that deliver infrastructure, determine policies, set regulations and rules and finally at the meta-level, the focus was more regional, or cross country or global levels. The first category, micro-level, 
recorded 89 papers, 50 for journals and 39 for conferences representing 71.77percent. Meso level also recorded 23 articles, 10 for conferences and 13 for journals representing 18.55 percent, 3 articles each were found in macro and meta-levels for both conferences and journals representing 4.84percent respectively. Four (4) articles were not classified under any of the levels; therefore these papers were not analyzed under this section.

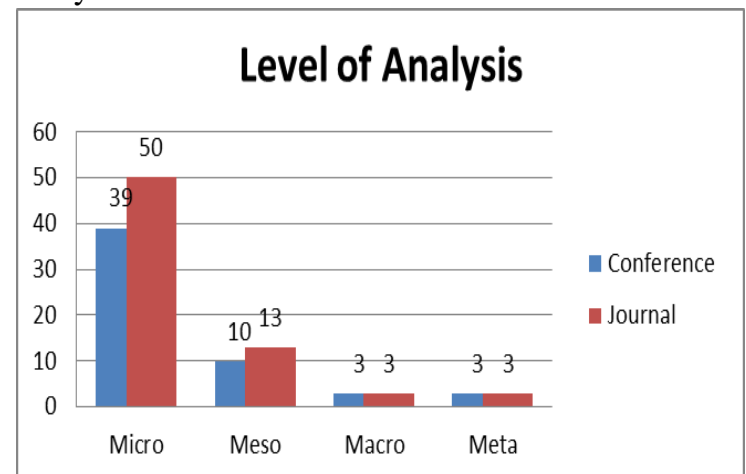

Fig. 4: Literature classification based on the level of analysis

\subsection{Geographical focus}

Fifteen 15 conference articles and 24 journal articles totaling 39 which represented 30.5percent were recorded from Asia as the highest followed by 17 conference articles, 20 journal articles totaling 37 articles representing 28.9percent were recorded for global, these articles focused on global issue or data were collected online (globally). North America recorded 7 conference articles and 10 journal articles totaling 17 articles representing 13.3 percent. Europe also recorded 7 conference articles and 8 journal articles representing 11.7percent.

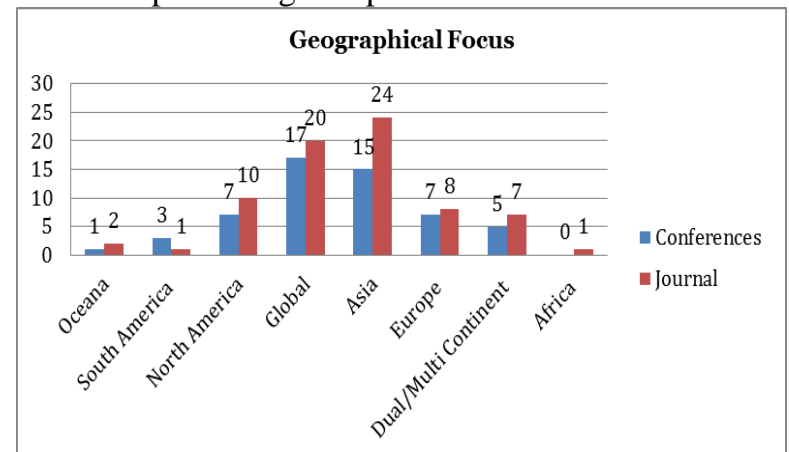

Fig. 5: Literature classification based on geographical focus

Some articles focused on or collected data on more than one continent. These articles were categorized under the Dual/ Multi category, 5 articles were recorded for conferences, and 7 articles for journals totaling 12 articles recorded and used for this review.
South America recorded 3 conference articles and 1 journal article, which represented 3.1percent. Oceana had a conference article and 3 journal articles used for this review. No conference publication and 1 journal article was recorded for Africa.

\subsection{Research frameworks / models / theories}

There was a categorization based on frameworks, models, and theories that were used in the publications accepted for this review. The most dominant theory used in 7 papers representing 5.5percent was the Technology Acceptance Model (TAM). This was followed by Flow theory used in 6 papers $(4.7 \%)$, Uses and Gratification Theory and Expectation Confirmation Theory were both used in 5 papers representing 3.9 percent. Cognitive Behavioral Theory was used in 4 papers which amounted to 3.1 percent. The Theory of Self-Regulation and Self-Control Theory were used in 3 papers which resulted in 2.3 percent each. Unified Theory of Acceptance \& Use of Technology (UTAUT), Social Cognitive Theory, Media System Dependency (MSD) Theory and Attachment Theory were used 2 times each, which resulted in 1.6percent respectively. The rest of the theories such as Diffusion Theory, Sensitivity Theory, Reinforcement Sensitivity Theory, Theories of Reward and Self-Control, Depletion Theory of Self-Control, Social Exchange Theory, Rational Addiction Theory, Theory of Consumption Values, Actor-Network Approach, Unified Theory of Acceptance \& Use of Tech. (UTAUT) 2, Self-Control Framework, Diffusion of Innovation Theory (DOI), Cognitive-Behavioral Model of Pathological Internet Use, Cultural Dimension of Uncertainty Avoidance, Theory of Cognitive Dissonance, Five-Factor Model (FFM), Social Identity Theory, Grounded Theory, Transactional Model of Stress, Learning theory, Stimulus-Organism-Response Model, Attribution-Theory, "Technology-Family Conflict" (TFC), Zaltman Metaphor Elicitation Technique (ZMET), Four-Category Motivation Framework, Cognitive Model of Addictive Behavior, Consumer Value Theory, Player Motivation Model, Theory of Conditioning, General Strain Theory, Self Determination Theory, Extended Self-Theory, Use Diffusion Model, Hierarchical Model of Personality, Psychodynamic Theory, The demand Control Model, Activity Theory, Resource-Based Theory, Typological Theory, Structuration Theory, Dual Systems Theory, Mass Communication Theory were used only once each which resulted to 0.8 percent respectively. According to the review, 42 papers representing 32.8percent did not use any theory or model or research framework to guide their work, however, 86 articles representing 67.2percent used different theories, models, and frameworks. 


\section{Discussions}

\subsection{Publication outlets}

The findings revealed Computers in Human Behavior produced the highest number of publications accepted and used for this review. This was possible because this journal accepted articles from varied backgrounds such as information systems, psychology, management, health, media and communication, computer science and several other disciplines. This shows that smartphone addiction is a multidisciplinary issue and must be tackled from diverse disciplines.

Since this review is mainly focused on IS, the IS basket of 8 journals were searched individually, although 4 of the journals did not report anything, it helped the researchers to accept more papers from European Journal of Information Systems, and Information Systems Journal as indicated in the findings.

It also emerged that conferences with high publications on smartphone addictions had track sessions dedicated to the dark side of ICT, humancomputer interactions or related track sessions that helped to accept papers on the negative usage of technologies / ICT and by inference smartphone addictions.

In terms of journals, Children and Youth Services Review, International Journal of Human-Computer Interaction, Psychiatric Research and came third, these were also possible because smartphone addiction was researched from gender, age, the effect on health and well-being of individuals in different cultures and on human and computer interactions.

\subsection{Research themes}

The conference papers reviewed for this work have been categorized into 4 themes as pre-addiction, addiction, post addictions, and pre/post addictions. The findings depicted that scholars researching from the pre-addiction subtheme tried to research into smartphone addictions by finding out from different perspectives as to how users become addicted to smartphones. This theme focused on the causes of smartphone addictions. Researchers from this perspective used theories, frameworks, and models to find out the processes that lead to smartphone addictions. Others focused on the various technological artifacts and applications on the smartphones that may lead to SA. This group of scholars may be researching from technical perspectives. Other researchers using the subtheme pre-addiction sought to find out the role of human elements like flow, motives, reinforcement, rewards, and so on that may cause or lead users to become addicted. This group of researchers looked at addiction from a social perspective. It would, therefore, be important to examine the issue of smartphone addiction from a sociotechnical perspective.

The second theme was categorized under addiction. This theme looked at the prevalence, pervasiveness, and predominance among diverse smartphone different user groups. Papers in this category tried to examine the smartphone addictive behaviors among different cultures, different age groups, and countries. For example, Korea versus the USA, compared the dominance of SA between 2 or more continents, etc[54].

The third highest subtheme was post-addiction. This category of researchers looked at the psychological, physiological, social and other consequences of the addiction on the addicts' lives and extended that to the effect of the addiction on their immediate environment, their friends, families, and communities. This category was hugely dominated by health practitioners. Some scholars looked at discontinuation, treatment and other measures that could be deployed to recover from addiction. This review revealed that while some researchers looked at social factors that could help discontinue addiction, others were concerned about the technical knowledge, artifacts, and techniques that could help curb addiction.

The fourth category of papers looked at pre/postaddiction. This was the least subtheme identified and scholars in this category tried to combine the three previous subthemes discussed thus investigate into factors leading to smartphone addiction, prevalence and the consequences of addictions in one paper. These researchers tried to find the cause and treatment of smartphone addiction in one single publication. Again, some researchers tried to do this from a technical perspective while others tried to do this from a social perspective. There is, therefore, the need to consider a socio-technical perspective going forward. Since the pre/post addiction subtheme covers from causes to consequences of addiction, but, was found to be the least of the four subthemes, there is the need to encourage more research in this category and especially focus on sociotechnical perspective to provide more knowledge on social and technical dynamics of the problem.

\subsection{Conference publications per year}

The actual classification by year was 2007 to June 2018, which is within 10 years, six months period. As of June, only PACIS publications were covered for 2018. The results showed that although some works are being done on smartphone addiction, there is more room for improvement. From 2012, there has been an increase in the number of papers accepted every year on smartphone addiction. Even the articles accepted and used in this review were more for the first half of 2018 compared to the first half of 2017. 


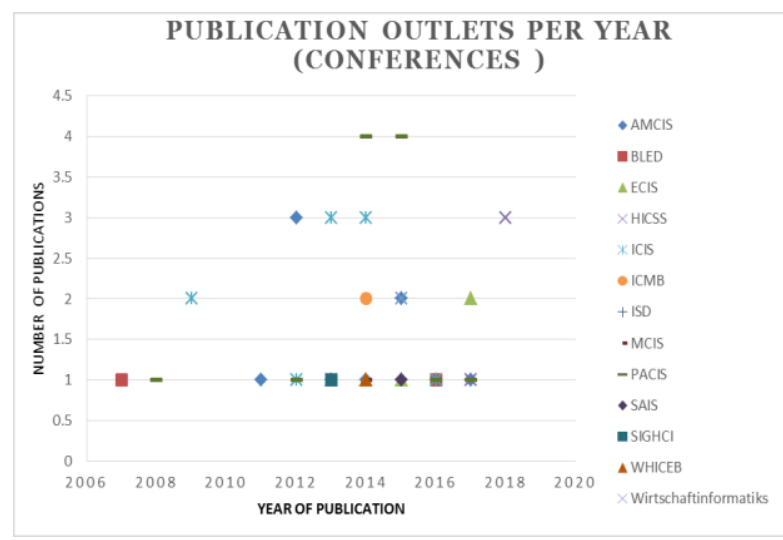

Fig 6: Literature Classification Number of Publications per Year for Conferences and Journals

Although some work is being done, there is the need to engage more the attention of IS scholars to publish on smartphone addiction.

\subsection{Research methodology}

The papers reviewed for this work were categorized based on quantitative, qualitative, mixed methodology and design science. After the analysis, the quantitative methodology recorded the highest articles. The main instrument used in collecting data was questionnaire through online or offline surveys. The Structure Equation Modeling (SEM) by using SmartPLS, Amos or R Studio was mostly used. This was followed by qualitative. The leading software used for qualitative analysis was N'vivo. One qualitative which was found interesting was a paper that collected data by using functional magnetic resonance imaging or functional MRI (fMRI) to compare brain activity across participants. Several others used different methods namely: MEC analysis, a corpus tool (VoyantTools), Windows 22.0, a two-tailed Wilcoxon test with normal approximation, SmartUnitn Social Media App, Nielsen Mobile App., and so on. The main methods used for collecting data for the qualitative articles were reviews, semi-structured questionnaire, focused groups, interviews, and observations. However, some papers did their analysis without the help of any software.

The mixed-method combined both quantitative and qualitative methods for analysis. For example, some of the papers in this category combined questions through surveys and interviews or reviews to collect data and used SPSS, N'vivo, and excels at analyzing data. The last category comprises experiments and simulations usually used in designed science research. These papers used a multi-method approach in collecting data, i.e. lab work, design, survey, and interviews to collect data, but the software used for their analysis was not known.

\subsection{Level of analysis}

The level of analysis classification of smartphone addiction was done based on micro, meso, macro and meta levels. Micro-level came first followed by Meso level. These researchers focused on the smartphone industry or IT use and addiction as a whole by comparing different artifacts, e.g. comparing different types of games to find out which is more addictive, rivalry among smartphones, example; Samsung and iPhone; and comparing different social media apps. The third category is the macro level of analysis. These papers focused on national / country levels, for example, smartphone addiction or compulsive use among Brazilian executives and professionals, segmenting the United Kingdom (UK) mobile fashion consumer. These researches may have a way of determining policy and set rules and regulations around smartphone addiction in the respective countries.

The last category is the meta-level of analysis where the focus is beyond one country or nation and is cross country. This shows that there is a limited research at meta and macro levels, this is the level of analysis gap identified in the literature. The researchers consider this extraction as very important because it shows clearly that more research is needed at the meta and macro levels to inform policymakers, developers, and other industry players about the harmful effect of SA. This would help direct government policies, enact rules and regulations and put necessary measures to curb or regulate these kinds of behavioral addictions. This corroborates the effort of the American Psychiatric Association (APA) who stated that the closest form of behavioral disorder, Internet Gaming Disorder (IGD) which even sometimes causes users to eventually become addicted to their smartphones, as a behavioral disorder that needs additional scientific research[55].

\subsection{Geographical focus}

This classification examines smartphone addiction research based on the geographical focus of the extant literature. In this discussion, the researchers combined both the continent focus and country focus to help in the discussion under geographical focus. Two things were considered, which were the sources of the data collection and the focus of the article under review. Firstly, the findings revealed that the highest publication came from Asia and the articles came from China, Hong Kong, Korea, Singapore, and Taiwan. Secondly, the articles focused on global issues or collected data online (globally). North America came third and the USA and Canada led the research. There were a lot of publications from the USA, but most of them were done in collaboration with fellow researchers from different continents and data was also collected specifically from two or more continents. Therefore these papers were 
categorized under a dual/multi-continent group. Other countries in this category were China, Australia, Ireland, Germany, Hong Kong, Korea, France, and Finland. Europe and was represented by the United Kingdom, Germany, Turkey, Greece, and Austria. Only Brazil represented South America, and the Oceana continent was represented by New Zealand and Australia.

Asia recording the highest articles accepted for this review was largely influenced by conferences and journals from the Asian continent. It was noticed that the authors' geographical locations had so much influence on their publication outlets. Technology addiction and for that smartphone addiction is being seriously given attention by academics or research community in both Asia and North America continents. This has so much implication on their approaches adopted in mitigating the menace. For example; technology addiction research and rehabilitation centers are being built across several cities on both continents to mitigate or lessen the effect of TA on these continents.

The findings also revealed that Africa recorded only one journal article published from Mauritius used for this work. Therefore this review from Africa is very important. It also throws a challenge to scholars to begin some work on the African continent on technology addiction in general and smartphone addiction, in particular, having in mind that smartphone penetration was estimated to grow at 52.9 percent on year by year basis. In 2017, it was estimated that 293.8 million people were smartphone users on the continent of Africa and by 2021, this figure may increase to 929.9 million which put Africa as one of the leading continents with smartphone usage[56]. Currently, there are only two technology addictions centers located in South Africa and Algeria respectively which are also Clinics for treatment or rehabilitation of addicts.

\subsection{Research frameworks / theories / Models}

A theory is a "coherent set of general propositions used as principles of explanation, understanding, and prediction of the apparent relationships of certain observed phenomena" [57]. Conceptual frameworks or approaches are analytical schemes that simplify reality to make it easier to discuss, analyze or research. The two simplify reality by selecting certain phenomena/variables and suggesting certain relationships between them [58]

It is important to note that this review has failed to establish a causal theory that took care of the urge or craving phenomenon. While some of the theories used for researching into SA were borrowed from other disciplines and therefore did not consider IS design principles in tackling the menace, theories adopted from IS also lack the ability to describe, explain, and predict SA. According to the review, 42 papers did not use any theory or model or research framework to guide their work, however, 86 articles used varied theories, models, and frameworks. It would, therefore, be useful to purposely develop a causal theory using IS design principles to mitigate SA.

\section{Conclusions, Limitations and Future Research Directions}

In conclusion, literature revolves around antecedents or what drives users to become addicted to smartphones such as; user characteristics, individual behavioral types, personality, and psychological traits, social interactions, reinforcing compulsive behaviors, habits, and social presence. Smartphone addiction consequences or outcomes were linked to family dysfunction, poor academic and work performance, health complications, and social problems. These studies were conducted among genders, and age groups. They were based on individual, organizational, country, and global levels. Predictors of SA were also studied around SNS, Facebook, Games, and so on. Technology drivers and characteristics were also broadly studied around IT design artifacts, IT identity, smartphone features, IT desirability, reinforcing and inducing features on smartphones. While some researchers concentrated on technical perspective such as IT artifacts, other scholars concentrated on social aspects of SA. There is, therefore, the need to combine both the technological and social aspect of SA to have a holistic view of the problem.

To fully understand these subthemes and also establish the level of analysis gap, this piece of work categorized the papers based on the micro, meso, macro, and meta level of analysis which revealed that, macro (national) and meta (global) levels were least researched. Therefore, future research should be directed towards national and global levels to help policymakers, policy implementers, governments, smartphone manufacturers and users on developing policies to regulate the industry.

This paper identified that several theories or models used in IS literature failed to establish a causal theory that fully accounted for urge phenomena in the interaction between technical features and user characteristics. Future research, therefore, should look at developing a causal theory that would explain and predict addiction to technologies by regulating the urge and craving phenomena.

In terms of the methodological gap, this paper has clearly shown that apart from quantitative, all the other methodological approaches were not used much. 
Therefore, for future research, the concentration should be on qualitative, mixed methods and simulations or design science research method to reveal the beyond the figures, the structure and causal mechanisms that easily influence users to become addicted to smartphones. In terms of context and geographical gaps, Asia leads the chart, Africa recorded only one paper recorded and used for this paper that throws a massive challenge to the IS community, especially those on the continent of Africa and African descent. Africa may have to double up the effort to prepare against SA insurgency, which is becoming a global menace.

Future research may have to focus on addictive applications rather than the devices because research on smartphone addiction is like calling "food addiction" as "kitchen addiction". Food is usually prepared and served from the kitchen. Therefore, there may be a strong correlation between "kitchen addictions" and "food addiction", but the two are not the same, sometimes food could be prepared from elsewhere and not necessarily in the kitchen. Scholars should, therefore, be looking at the applications on smartphones, and what the devices are being used for instead of focusing just on the artifacts.

This review paper posited that the issue of smartphone addiction is a multidisciplinary issue, therefore, stakeholders from diverse backgrounds such as users, policymakers, regulators, manufacturers, and academics must be involved to find an antidote to the problem. Journals that accept articles from varied backgrounds may have more papers than those that do not. Other IS conferences may take a cue from HICSS and start promoting research on the "Dark Side of ICT" to help in finding solution to the problem from Information Systems (IS) perspective.

\section{References}

[1] I. Vaghefi, L. Lapointe, and C. Boudreau-Pinsonneault, "A typology of user liability to IT addiction," Inf. Syst. J., vol. 27, no. 2, pp. 125-169, 2016.

[2] J. D. Elhai, J. C. Levine, R. D. Dvorak, and B. J. Hall, "Non-social features of smartphone use are most related to depression, anxiety and problematic smartphone use," Comput. Human Behav., vol. 69, pp. 75-82, 2017.

[3] S. H. Jeong, H. Kim, J. Y. Yum, and Y. Hwang, "What type of content are smartphone users addicted to?: SNS vs. games," Comput. Human Behav., vol. 54, pp. 1017, 2016.

[4] É. Duke and C. Montag, "Smartphone addiction, daily interruptions and self-reported productivity," Addict. Behav. Reports, vol. 6, no. July, pp. 90-95, 2017.

[5] L. Lapointe, C. Boudreau-Pinsonneault, and I. Vaghefi, "Is smartphone usage truly smart? A qualitative investigation of IT addictive behaviors," Proc. Annu. Hawaii Int. Conf. Syst. Sci., no. January 2013, pp.
1063-1072, 2013.

[6] M. Griffiths, "Technological addictions," in Clinical psychology forum, 1995, p. 14.

[7] K. S. Young, "Internet addiction: Symptoms, evaluation, and treatment," Innov. Clin. Pract. (Volume 17), 1999.

[8] W. K. Bickel, A. L. Odum, and G. J. Madden, "Impulsivity and cigarette smoking: Delay discounting in current, never, and ex-smokers," Psychopharmacology (Berl)., vol. 146, no. 4, pp. 447454, 1999.

[9] B. H. Baltagi and J. M. Griffin, "Rational addiction to alcohol: Panel data analysis of liquor consumption," Health Econ., vol. 11, no. 6, pp. 485-491, 2002.

[10] M. Grossman and F. J. Chaloupka, "The demand for cocaine by young adults: a rational addiction approach," J. Health Econ., vol. 17, no. 4, pp. 427-474, 1998.

[11] J.-L. Liu, J.-T. Liu, J. K. Hammitt, and S.-Y. Chou, "The price elasticity of opium in Taiwan, 1914--1942," J. Health Econ., vol. 18, no. 6, pp. 795-810, 1999.

[12] N. Olekalns and P. Bardsley, "Rational Addiction to Caffeine: An Analysis of Caffee Consumption," J. Polit. Econ., vol. 104, no. 5, pp. 1100-1104, 2016.

[13] P. Mobilia, "Gambling as a rational addiction," $J$. Gambl. Stud., vol. 9, no. 2, pp. 121-151, 1993.

[14] G. T. Smith, S. Fischer, M. A. Cyders, A. M. Annus, N. S. Spillane, and D. M. McCarthy, "On the validity and utility of discriminating among impulsivity-like traits," Assessment, vol. 14, no. 2, pp. 155-170, 2007.

[15] O. Turel, A. Serenko, and P. Giles, "Integrating technology adddiction and use: An empirical investigation of online auction users," MIS Q., 2011.

[16] Q. Li, X. Guo, and C. Sun, "the Shadow of Microblogging Use: Relationship Between Usage Types and Addiction," Icis, vol. 9, no. 2, pp. 579-612, 2012

[17] S. P. Zwanenburg, "Information Technology Addiction: Construct Development and Measurement," Icis-Rp, vol. 1 , no. 4, pp. 21-37, 2013.

[18] J. P. Charlton and I. D. W. Danforth, "Distinguishing addiction and high engagement in the context of online game playing," Comput. Human Behav., vol. 23, no. 3, pp. 1531-1548, 2007.

[19] L. Vinet and A. Zhedanov, "A 'missing' family of classical orthogonal polynomials," Games Cult., vol. 17, no. 2, pp. 1-16, Nov. 2010.

[20] A. Akin and M. İskender, "Internet Addiction and Depression, Anxiety and Stress," Int. Online J. Educ. Sci., vol. 3, no. 1, pp. 138-148, 2011.

[21] R. Jia and H. H. Jia, "Factorial validity of problematic Internet use scales," Comput. Human Behav., vol. 25, no. 6, pp. 1335-1342, 2009

[22] O. Turel and A. Serenko, "Is mobile email addiction overlooked?," Commun. ACM, 2010.

[23] H. Huang and L. Leung, "Instant Messaging Addiction among Teenagers in China: Shyness, Alienation, and Academic Performance Decrement," Cyberpsychol. Behav., vol. 12, pp. 675-679, 2009.

[24] H. Huang and L. Leung, "Instant messaging addiction among teenagers in China: shyness, alienation, and academic performance decrement," CyberPsychology Behav., vol. 12, no. 6, pp. 675-679, 2009.

[25] O. Turel, A. Serenko, and P. Giles, "Integrating 
Technology Addiction and Use: An Empirical Investigation of Online Auction Users," MIS Q., 2011.

[26] C. S. Andreassen, "Online Social Network Site Addiction: A Comprehensive Review," Curr. Addict. Reports, vol. 2, no. 2, pp. 175-184, 2015.

[27] I. Vaghefi, "From IT Addiction to Discontinued Use : A Cognitive Dissonance Perspective," in Proceedings of the 50th Hawaii International Conference on Systems Sciences, 2017, pp. 5650-5659.

[28] I. Vaghefi, "Personality Predictors of IT Addiction," vol. 9, no. January, pp. 5274-5283, 2018.

[29] X. Carbonell, U. Oberst, and M. Beranuy, "The cell phone in the twenty-first century: A risk for addiction or a necessary tool," Princ. Addict. Compr. Addict. Behav. Disord., vol. 1, pp. 901-909, 2013.

[30] T. T. C. Lin and Y. H. Chiang, "Investigating predictors of smartphone dependency symptoms and effects on academic performance, improper phone use and perceived sociability," Int. J. Mob. Commun., vol. 15 , no. 6, pp. 655-676, 2017.

[31] W. Webb, "From" cellphone" to" remote control on life": how wireless communications will change the way we live over the next 20 years," in Radio Frequency Integrated Circuits (RFIC) Symposium, 2002 IEEE, 2002, pp. 7-11.

[32] S. Butt and J. G. Phillips, "Personality and self reported mobile phone use," Comput. Human Behav., vol. 24, no. 2, pp. 346-360, 2008.

[33] L. Leung and R. Wei, "Who are the mobile phone have-nots? Influences and consequences," New Media Soc., vol. 1, no. 2, pp. 209-226, 1999.

[34] R. Ling, "'We will be reached': The use of mobile telephony among Norwegian youth," Inf. Technol. People, vol. 13, no. 2, pp. 102-120, 2000.

[35] C. Elie-Dit-Cosaque, J. Pallud, and M. Kalika, "The Influence of Individual, Contextual, and Social Factors on Perceived Behavioral Control of Information Technology: A Field Theory Approach," J. Manag. Inf. Syst., vol. 28, no. 3, pp. 201-234, 2011.

[36] A. Oulasvirta, T. Rattenbury, L. Ma, and E. Raita, "Habits make smartphone use more pervasive," Pers. Ubiquitous Comput., vol. 16, no. 1, pp. 105-114, 2012.

[37] D. Amin, "Going off the mobile grid Daven Amin Dynamics of Human Health; 2014:1(2)," vol. 1, no. 2, 2014.

[38] L. A. Perlow, "Breaking the Smartphone Addiction," pp. 1-2, 2012.

[39] Jia, H. Hartke, and J. Pearson, "Can Computer Playfulness and Cognitive Absorption Lead to Problematic Technology Usage?," ICIS 2007 Proc., 2007.

[40] J. Iivari, R. Hirschheim, and H. K. Klein, "Process knowledge in two IS journals," Inf. Syst. J., vol. 14, pp. 313-342, 2004.

[41] J. Webster and R. T. Watson, "Analyzing the Past to Prepare for the Future: Writing a Literature Review," MISQ Q., vol. 26, no. 2, pp. xiii-xxiii, 2002.

[42] I. Newton, "Letter to Robert Hooke, February 5, 1676,"
Corresp. Isaac Newt., vol. 7, pp. 1661-1675, 1959.

[43] R. M. Davison, G. J. de Vreede, and R. O. Briggs, “On Peer Review Standards For the Information Systems Literature," Commun. Assoc. Inf. Syst., vol. 16, no. January, pp. 1-6, 2005.

[44] J. D. Elhai, R. D. Dvorak, J. C. Levine, and B. J. Hall, "Problematic smartphone use: A conceptual overview and systematic review of relations with anxiety and depression psychopathology," J. Affect. Disord., vol. 207, no. February 2016, pp. 251-259, 2017.

[45] J. De-Sola Gutiérrez, F. Rodríguez de Fonseca, and G. Rubio, "Cell-Phone Addiction: A Review," Front. Psychiatry, vol. 7, no. OCT, Oct. 2016.

[46] M. Tarafdar, A. Gupta, and O. Turel, "The dark side of information technology use," Inf. Syst. J., vol. 23, no. 3, pp. 269-275, 2013.

[47] M. I. Hwang and R. G. Thorn, "The effect of user engagement on system success: A meta-analytical integration of research findings," Inf. Manag., vol. 35, no. 4, pp. 229-236, 1999.

[48] S. Petter and E. R. Mclean, "Information \& Management A meta-analytic assessment of the DeLone and McLean IS success model : An examination of IS success at the individual level," vol. 46, pp. 159-166, 2009.

[49] R. Duncombe and R. Boateng, "Mobile Phones and Financial Services in Developing Countries: A review of concepts, methods, issues, evidence and future research directions," Third World Q., vol. 30, no. 7, pp. 1237$1258,2009$.

[50] E. W. T. Ngai and F. K. T. Wat, "A literature review and classification of electronic commerce research," Science (80-. )., vol. 39, pp. 415-429, 2002.

[51] H. Yang and M. Tate, "A Descriptive Literature Review and Classification of Cloud Computing Research," Commun. Assoc. fot Inf. Syst., vol. 31, no. 2, pp. 34-61, 2012.

[52] T. Chan, C. Cheung, Z. Lee, and T. Neben, "The Urge to Check Social Networking Sites: Antecedents and Consequences," PACIS Proc., p. Paper 33, 2014.

[53] W. Li, E. L. Garland, and M. O. Howard, "Family factors in Internet addiction among Chinese youth: A review of English- and Chinese-language studies," Comput. Human Behav., vol. 31, no. 1, pp. 393-411, 2014.

[54] L. Y. Shin, "Smartphone Usage Pattern and Addiction Probability: A Comparative Analysis between U.S. and Korea," 2013.

[55] APA, “APA (2013),” Diagnostic Stat. Man. Ment. Disord., vol. 5, 2013.

[56] G. Boateng and V. Kumbol, "Project iSWEST: Promoting a culture of innovation in Africa through STEM," in Integrated STEM Education Conference (ISEC), 2018 IEEE, 2018, pp. 104-111.

[57] W. G. Zikmund, "Business research methods 7th ed., Thomson/South-Western.” Appendices, 2003.

[58] C. Fisher, Researching and writing a dissertation: an essential guide for business students. Pearson Education, 2010. 